\title{
Inequalities in the application of welfare sanctions in Britain
}

\section{Robert de Vries, Aaron Reeves and Ben Geiger}

Working paper 15

August 2017 


\section{LSE International Inequalities Institute}

The International Inequalities Institute (III) based at the London School of Economics and Political Science (LSE) aims to be the world's leading centre for interdisciplinary research on inequalities and create real impact through policy solutions that tackle the issue. The Institute provides a genuinely interdisciplinary forum unlike any other, bringing together expertise from across the School and drawing on the thinking of experts from every continent across the globe to produce high quality research and innovation in the field of inequalities.

For further information on the work of the Institute, please contact the Institute Manager, Liza Ryan at e.ryan@lse.ac.uk.

International Inequalities Institute

The London School of Economics and Political Science

Houghton Street

London

WC2A 2AE

Email: Inequalities.institute@lse.ac.uk

Web site: www.lse.ac.uk/III

@LSEInequalities

f LSE Inequalities

(C) Robert de Vries, Aaron Reeves and Ben Geiger. All rights reserved.

Short sections of text, not to exceed two paragraphs, may be quoted without explicit permission provided that full credit, including (c) notice, is given to the source. 


\begin{abstract}
Unemployed people in Britain who are in receipt of government welfare benefits can have these benefits stopped if they fail to comply with certain conditions. Such a stoppage is known as a 'benefit sanction'. The present working paper has two aims: i) to provide an introduction to British system of sanctions, specifically as it applies to unemployed people who are not disabled, and ii) to identify demographic inequalities in the application of sanctions. Using data published by the UK Department of Work and Pensions, we find that some groups of unemployed claimants (younger people, men, and ethnic minorities) are at substantially higher risk of experiencing a sanction. This working paper will be updated at a later date with analyses investigating the drivers of this inequality.
\end{abstract}




\section{Introduction}

Most unemployed people of working age in the UK are entitled to receive public welfare support in the form of direct cash payments. The primary cash benefit programme for unemployed people who are not disabled is Jobseeker's Allowance (JSA), ${ }^{1}$ which can be claimed on the condition that the unemployed person is actively seeking work. Claimants can have their benefit payments temporarily stopped (a benefit 'sanction') if they are found to be in violation of the terms of JSA receipt: for example, if they fail to attend (or arrive late to) a meeting with their caseworker (Jobcentre personal adviser), or if they are judged not to be making enough effort to seek work.

The system of benefit sanctions in the UK has generated a great deal of debate, both in the media, and among policymakers. A 2014 inquiry by the House of Commons Work and Pensions Committee into the sanctions regime attracted a large number of critical submissions. These included reports by 'whistle-blowing' Jobcentre staff about malpractice and poor treatment of claimants, as well as numerous submissions (by charitable organisations and by claimants themselves) describing the mental and physical health consequences of stopped payments. ${ }^{2}$ Beyond the inquiry, academic authors have also linked the sanctions regime with negative social outcomes, such as increased use of food banks (Loopstra et al., 2015a; 2016), and have questioned its effectiveness in improving employment outcomes. For example, Loopstra et al. (2015b) found that higher sanction rates led to a greater number of people ceasing to claim JSA, but did not increase employment rates.

In this paper, we focus on the question of potential inequalities in the application of sanctions. Are some JSA claimants - for example claimants from particular ethnic groups - at greater risk of being sanctioned than others? Despite this question being included in the terms of reference of the 2014 House of Commons inquiry ${ }^{3}$ relatively little systematic research has been conducted. To our knowledge, only three statistical analyses of demographic inequalities in JSA sanction rates have been published. The first is an analysis by the New Policy Institute (2014) of data from 2013-14, which found that younger claimants were more likely to be sanctioned than older claimants and that men were more likely to be sanctioned than women. The second is contained in a report by the UK Welfare Conditionality Project (Watts et al., 2014). This analysis also found that 18-24 year old claimants were substantially more likely to be sanctioned than claimants from other age groups, and that this age-related inequality remained stable from 2000 to 2014. Finally, Reeves \& Loopstra (2017) found that local

\footnotetext{
1 From 2013, a proportion of claimants who would previously have been eligible for a specific type of JSA (based on income levels rather than previous tax contributions) have been transferred to the new Universal Credit (UC) programme. However, as of the end of 2016, the majority of claimants were enrolled on JSA rather than UC.

${ }^{2}$ A full list of written submissions can be found at http://www.parliament.uk/business/committees/committees-a-z/commons-select/work-and-pensionscommittee/inquiries/parliament-2010/benefit-sanctions/?type=Written\#pnIPublicationFilter ${ }^{3} \mathrm{https}: / /$ www.parliament.uk/business/committees/committees-a-z/commons-select/work-andpensions-committee/news/benefit-sanctions-launch/
} 
authorities with higher proportions of ethnic minority claimants had slightly higher rates of JSA sanctions (though this association was not robust to adjustment for claimant characteristics, such as the length of claims).

In the present paper, we use more recent data (through to the end of 2016) to take a more detailed look at demographic inequalities in the application of sanctions (including an analysis of the reasons why different groups are referred for sanction). The question of whether some groups of claimants are at greater risk of sanction than others is particularly important given the large degree discretion caseworkers are able to exercise in the application of sanctions.

In order to claim JSA, eligible claimants must have an initial interview with a personal adviser ${ }^{4}$ at their local Jobcenter Plus office. During this interview, the claimant must sign a 'Claimant Commitment' outlining the steps they will take to find work. Claimants must then continue to attend regular interviews with their personal adviser over the course of their claim. Personal advisers have a dual role: 1 ) helping the claimant find work and, 2) assessing whether the claimant has violated the conditions of their benefit. In the latter case, the adviser is required to refer the claimant for a sanction. There are a number of violations for which personal advisers (and other Jobcentre staff) can refer a claimant for a sanction. These include "Failure to attend or participate in an adviser interview without good reason" (this includes late attendance), "Not actively seeking work" (inadequate attempts to find work), and "Left employment without good reason". Appendix Table A1 provides a full list of reasons for referral.

After a claimant has been referred for a sanction, an independent Department for Work and Pensions (DWP) 'decision-maker' (a different staff member within Jobcentre Plus) makes the determination as to whether the sanction should be applied. If they decide the sanction should proceed, the claimant's benefit payments are stopped. At this point, the claimant may challenge the decision and present new evidence or arguments as to why they should not be sanctioned. The decision-maker will either accept these arguments and reverse the sanction, or reject them and keep it in place. If a claimant persists in challenging the decision after this point a (non-local) 'dispute resolution team' will reconsider the case and come to a final decision as to whether the sanction should be upheld or overturned. After this process is complete, if the claimant is still not satisfied with the outcome, they may appeal to an independent Social Security and Child Support Tribunal. ${ }^{5}$ If at any point in the process the sanction decision is overturned, the claimant is entitled to have missed payments refunded.

It should be noted that it is not only Jobcentre staff who can refer claimants for sanction. Between June 2011 and April 2017, the UK government operated a 'backto-work' scheme called the Work Programme. This scheme targeted claimants who had been on JSA for a year (less for younger claimants). Claimants mandated to participate in the Work Programme were assigned to external (public, private, or third

\footnotetext{
${ }^{4}$ In some cases, Jobcentre personal advisers are instead referred to as 'Work Coaches'.

${ }^{5}$ https://www.gov.uk/social-security-child-support-tribunal/before-you-appeal
} 
sector) organisations tasked with helping them prepare for and find work. Staff at these organisations were required to refer claimants for sanction if they were not fully complying with the programme. For example, claimants assigned to a Work Programme provider could be sanctioned if they did not "take part fully" in an activity mandated by the provider, such as a training session or work experience placement. ${ }^{6}$

Jobcentre personal advisers, Work Programme providers, and DWP decision-makers ${ }^{7}$ are given detailed guidance as to when a claimant should be referred for sanction and when a sanction should be applied (see footnote 4). Nevertheless, there remains considerable scope for individual discretion at each stage of the process. For example, a Jobcentre personal adviser may decide to be more or less lenient in referring a claimant for arriving late to an adviser Interview; or a decision-maker may be more or less strict in determining what constitutes acceptable evidence that a claimant had a 'good reason' for being late.

We are not aware of any academic research into welfare caseworker discretion in the UK. However, research on the US system has found that caseworker treatment of claimants is often highly variable. For example, allowances may be made for some clients who fail to meet a particular requirement, but not others (Brodkin, 1997; Meyers, Glaser, \& MacDonald, 1998; Hagen \& Ownes-Manley, 2002). Rules may be adhered to strictly in order to punish disfavoured claimants, or interpreted liberally to avoid causing harm to favoured clients.

Though detailed academic research is absent, there is nevertheless considerable evidence to support the idea that staff administering JSA in the UK exercise a high degree of discretion in the application of sanction rules, and that this results in the inconsistent treatment of claimants. A number of submissions to the 2014 House of Commons inquiry detail the various ways in which claimants may be treated more or less harshly by caseworkers. For example, in one submission, a Jobcentre personal adviser describes the pressure felt by staff at his Jobcentre to increase the number of claimants they referred for sanction, independent of claimant compliance (Longden, 2014). Longden notes that selected claimants were subjected to an "almost forensic" scrutiny of their job search activity in order to locate a reason to refer the claimant for sanction. A submission by the Public and Commercial Services Union (2014) ${ }^{8}$ provides evidence (in the form of emails from managers) of similar pressure on both Jobcentre personal advisers and decision-makers to increase their individual referral and sanction rates.

Further evidence of the scope of individual discretion in the application of sanctions comes from analyses of variation in referral and sanction rates. Analyses by both

\footnotetext{
${ }^{6}$ Guidance for Work Programme providers on raising 'compliance doubts' is provided here: https://www.gov.uk/government/uploads/system/uploads/attachment_data/file/624475/workprogramme-provider-guidance-chapter-6.pdf

${ }^{7}$ Throughout the rest of this paper, 'caseworker' is used as a generic term covering any staff member able to make decisions about whether to refer, apply, or uphold a sanction against a claimant.

${ }^{8}$ The trade union covering UK public sector workers, including Jobcentre Plus staff
} 
Webster (2014) and the National Audit Office (NAO; 2016) found large amounts of unexplained variation between Jobcentres in the proportion of claimants referred for sanction, with the NAO explicitly noting that this may be due to differences in the behaviour of personal advisers. The NAO analysis also found large unexplained differences in referral rates between Work Programme providers. Within regions, claimants were randomly assigned to a Work Programme provider - meaning that there should be no systematic differences in the composition of claimants assigned to each provider (NAO, 2016). Nevertheless, some providers referred much higher proportions of claimants for sanction than did others. ${ }^{9}$ This level of variation between Jobcentres and Work Programme providers suggests that similar claimants are receiving very different treatment when it comes to the application of sanctions.

One of the consequences of the discretion exercised by caseworkers (whether DWP staff or external providers) is that it increases the potential influence of individual biases and stereotypes - for example, based on ethnicity, gender, or age. In the US, Monat (2010) suggests that racial bias is one of the explanations for why Black and Latino claimants are more likely to receive a welfare sanction than are White claimants. Focusing on female claimants, she suggests that "Black and Latina participants may experience an increased risk of sanctions due to racialized stereotypes or ideologies held by caseworkers". Examples of such stereotypes include that claimants from these ethnic groups are "irresponsible" or have a "poor work ethic" (Monat, 2010, p.51). Similar ethnic attitudes and stereotypes (as well as those relating to age and gender) may also affect decisions made by welfare caseworkers in the UK, thereby potentially contributing to demographic inequalities in sanction rates.

The present working paper attempts to answer the following questions:

1. Which demographic groups are most likely to be referred for a JSA sanction?

2. Do demographic inequalities in referrals persist in final sanction decisions?

3. Are different demographic groups referred for sanction for different reasons?

4. Have demographic inequalities in referrals increased or decreased over time?

These analyses are not able to address the question of why demographic inequalities exist. Crucially they cannot determine whether inequalities result from structural factors, differences in claimant behaviour or differential treatment of claimants by caseworkers. We intend to expand this working paper in the future to include analyses focused on addressing this question.

\footnotetext{
${ }^{9}$ For example, in the West Midlands, Serco (a private provider) referred claimants at twice the rate of Interserve (another private provider).
} 


\section{Methods}

\section{Data}

Monthly data on the number of JSA claimants referred and sanctioned by age group, ethnicity, and gender were retrieved from the DWP Stat-Xplore website ${ }^{10}$ for the period November $2012^{11}$ to December 2016.

Monthly data on the total number of people claiming JSA in each month over the same period (the claimant count) were retrieved from Nomis, the Office for National Statistics (ONS) portal which hosts official UK labour market statistics. ${ }^{12}$

\section{Analyses}

The results below include two types of figures:

1. Referral rates. These are expressed as the percentage of JSA claimants referred for sanction per month (the total number of JSA claimants referred for sanction in a given month divided by the total number of people claiming JSA that month).

2. Sanction rates. These are expressed as the percentage of JSA claimants sanctioned per month (the total number of JSA claimants sanctioned divided by the total number of people claiming JSA).

There are two important points to note about these figures. First, the sanction counts published by the DWP on StatXplore only include sanctions applied after claimant challenges have been resolved. They do not include individuals who were sanctioned but later had this sanction overturned after a successful challenge. Because claimants whose sanction is overturned still have their benefit payments stopped (this money is only refunded later, often after a substantial delay), the sanction rate figures given below are an underestimate of the true number of claimants who experience the negative consequences of a benefit stoppage. Around $25 \%$ of JSA claimants challenge their sanction decision, and of these challenges, $75 \%$ are successful (Webster, 2016a), so this distinction is significant.

The second point to note is that both the sanction and referral rate figures represent the proportion of JSA claimants sanctioned or referred per month. As Webster (2016b) notes, they do not reflect (as has been suggested by a number of policymakers) the total proportion of JSA claimants who have ever received a sanction, or who have received a sanction in a given year. For example, in 2014, an average of $5 \%$ of claimants were sanctioned per month. However, $24 \%$ of people who claimed JSA in 2014 as a whole received a sanction that year (Webster 2016b). The latter figures are not published by the DWP and are therefore not included in this analysis.

\footnotetext{
10 https://stat-xplore.dwp.gov.uk/webapi/jsf/login.xhtml

11 In October 2012, rules on the application of sanctions were changed. Therefore all figures from November 2012 onwards are derived from consistent sanction rules.

12 https://www.nomisweb.co.uk/
} 
The analyses below also examine the proportion of referrals made for different reasons. These reasons are grouped into six categories for the purposes of analysis:

1. Failure to participate in the Work Programme. This category covers referrals made by external providers when claimants are judged not to be participating fully in the Work Programme.

2. Work focused interviews. This category covers referrals made by Jobcentre personal advisers for reasons relating to their meetings with claimants. This includes failure to attend (or late attendance at) adviser interviews without good reason and failure to comply with a Jobseeker's Direction without good reason. ${ }^{13}$

3. Availability for work. This category covers a number of reasons relating to the claimant not taking sufficient steps to seek work, or to apply for relevant jobs. It also covers claimants failing to accept job offers or not being available for work.

4. Other employment programmes. The DWP runs a number of employment programmes (for example training schemes) which do not fall under the banner of the Work Programme. Failure to participate fully in these schemes is also a reason for sanction referral.

5. Leaving previous employment. Claimants may be referred for sanction if they leave a job voluntarily without good reason, or if they lose a job due to misconduct.

6. Other reasons. Other referral reasons not covered under the previous categories, including trade disputes and joint claims exemptions ${ }^{14}$

Table A1 in the appendix gives the detailed breakdown of reasons in each category.

\section{Results}

\section{Demographic composition of JSA claimants}

In the median month over the period November 2012 to December 2016 there were 806,070 people claiming JSA in Great Britain. ${ }^{15}$ Table 1, below, gives the demographic composition of claimants in the median month.

\footnotetext{
${ }^{13}$ A Jobseeker's Direction is a course of action a personal adviser mandates a claimant to take to help them get work. For example, a claimant may be considered to be compromising their ability to get work by having an out of date CV. A Jobseeker's Direction may therefore be issued requiring the claimant to update their $\mathrm{CV}$. If the claimant fails to comply they can be referred for sanction.

14 Joint claims are when two members of a couple make a single joint JSA claim

${ }^{15}$ These statistics do not include Northern Ireland
} 
Table 1. Demographic composition of JSA claimants in the median month between November 2012 and December 2016

\begin{tabular}{lrl}
\hline $\begin{array}{l}\text { Male gender } \\
\text { Age group }\end{array}$ & $63.7 \%$ \\
& Under 18 & 0.1 \\
& $18-24$ & 22.9 \\
$25-49$ & 56.7 \\
& 50 & 20.6 \\
Ethnicity & \\
& White & 76.0 \\
Mixed & 2.1 \\
Asian or Asian British & 6.0 \\
Black or Black British & 7.5 \\
Chinese or other ethnic group & 2.6 \\
Prefer not to say & 4.2 \\
Unknown & 1.4 \\
\hline
\end{tabular}

\section{Total referrals and sanctions}

Over the period November 2012 to December 2016, an average (median) of $7.0 \%$ of JSA claimants per month were referred for sanction. Around half this figure $(3.6 \%)$ actually received a sanction.

Table 2 gives the proportion of referrals in each reason category. This shows that the most common reason for a referral was failure to participate in the Work Programme. $40 \%$ of all claimants referred were referred for sanction by external Work Programme providers. The next most common reasons for referral were work focused interviews (the most common specific reason within this category was failure to attend an adviser interview, representing $87 \%$ of all referrals in this category), and availability for work (the most common specific reason within this category was 'not actively seeking employment', representing $67 \%$ of referrals).

Table 2. Breakdown of referrals by referral reason (median month between November 2012 and December 2016)

\begin{tabular}{ll}
\hline Work programme & $39.0 \%$ \\
Work focused interviews & $21.1 \%$ \\
Availability for work & $21.5 \%$ \\
Other employment programmes & $7.6 \%$ \\
Leaving previous employment & $11.1 \%$ \\
Other referral reason & $0.6 \%$ \\
\hline
\end{tabular}

The dominance of the Work Programme is likely due to two factors. First, claimants participating in the Work Programme do not have regular contact with their Jobcentre personal advisers, and are therefore much less likely to be referred for other reasons 
(such as failing to attend an adviser interview). Second, unlike, Jobcentre personal advisers, who are permitted to evaluate whether a claimant had a 'good reason' for (for example) failing to attend an adviser interview, Work Programme providers are explicitly instructed not to consider whether or not a claimant had a good reason for in some way failing to participate fully in the work programme. This is spelled out in the guidelines for Work Programme providers: “. ...you have no option but to raise a doubt ${ }^{16}$ once the participant has failed to carry out a mandated activity, irrespective of whether or not they have offered an explanation afterwards" (p.6 of the guidance for Work Programme providers - see footnote 4). It is then up to the DWP decision-maker to determine whether or not the claimant had a good reason, and therefore whether the sanction should be applied. ${ }^{17}$

Are some groups of claimants more likely than others to be referred for sanction?

Figure 1 breaks down referral rates by age, gender, and ethnic group. The largest differences are between age groups. Overall, an average $10.8 \%$ of claimants between 18 and 24 are referred for sanction per month, compared to $6.5 \%$ of claimants between 25 and 49 , and $4.0 \%$ of claimants 50 and over.

This age difference exists within all ethnic groups and for both men and women. For example, among $18-24$ year old men, $11.7 \%$ of White, $13.8 \%$ of Black, and $12.2 \%$ of Asian claimants were referred for sanction per month. The corresponding figures for men aged $25-49$ were $6.9 \%, 7.6 \%$ and $7.5 \%$. Age differences for women were of a similar magnitude (the precise numbers behind Figure 2 are given in Table A2 in the appendix). The difference between the 18-24 and 25-49 groups was larger than the difference between the latter group and those who were $50+$.

\footnotetext{
16 I.e. refer the claimant for a sanction

${ }^{17}$ As noted above, despite these seemingly strict guidelines, there remain large differences in referral rates between Work Programme providers serving the same client base
} 


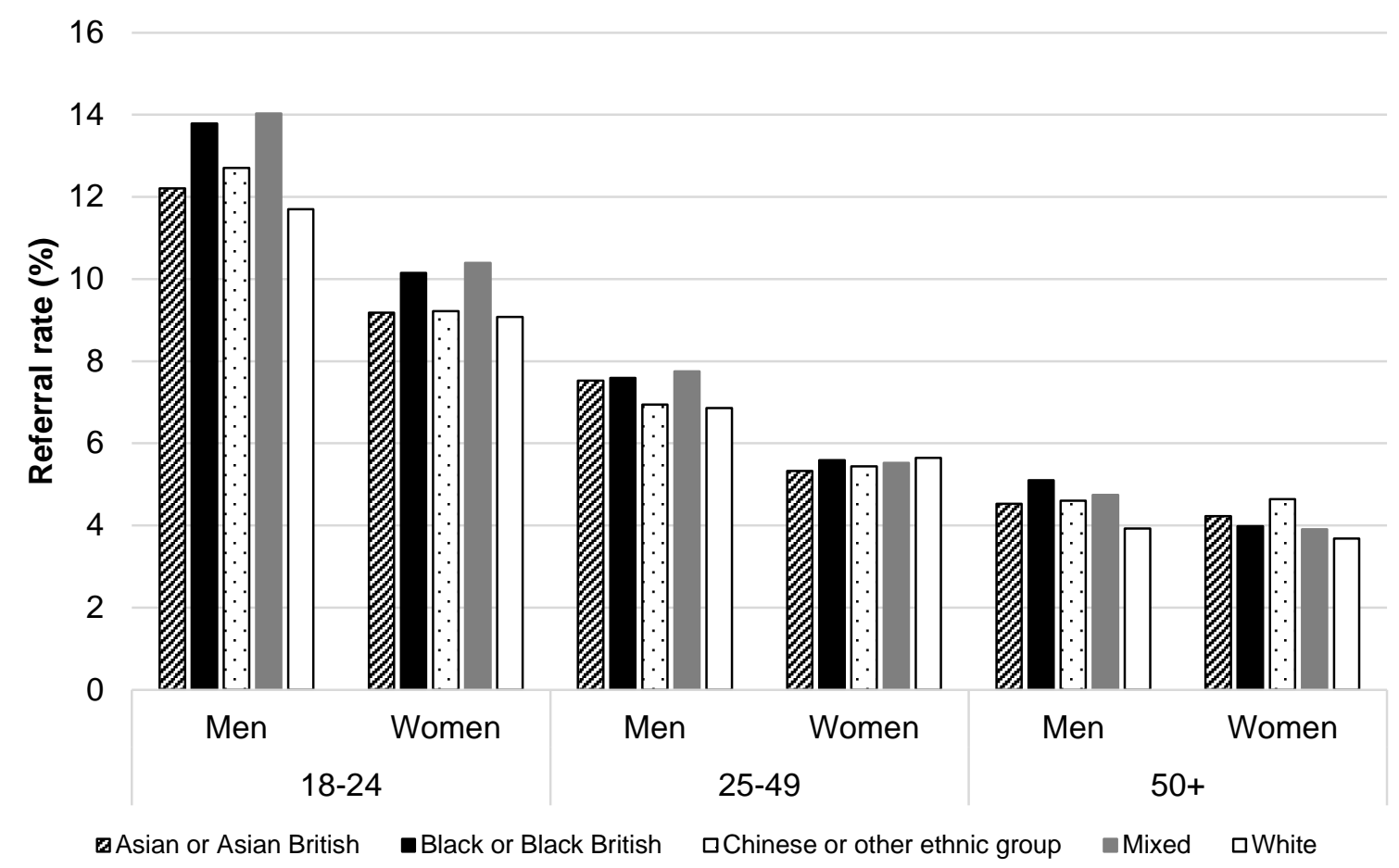

Figure 1. Median percentage of claimants referred per month by age, gender, and ethnicity (Nov 2012-Dec 2016)

Figure 1 also shows that men are more likely to be referred than women. Overall, an average of $7.5 \%$ of male claimants were referred for sanction per month, compared to $6.1 \%$ of female claimants.

This gender difference exists within almost all age and ethnic groups. For example, within the 18-24 year old age group, $11.7 \%$ of White men were referred for sanction compared to $9.1 \%$ of White women, $13.8 \%$ of Black men were referred compared to $10.2 \%$ of Black women, and $12.2 \%$ of Asian men were referred compared to $9.2 \%$ of Asian women. There are differences of a similar magnitude within the 25-49 year old age group. However, the differences are smaller (and in some cases non-existent) within the $50+$ age group. For example, in this age group $3.9 \%$ of White male claimants were referred for sanction, compared to $3.7 \%$ of White female claimants.

Ethnic inequalities are generally smaller than those according to age and gender. However, consistent patterns emerge. In almost all age and gender combinations White claimants are the least likely to be referred for sanction. For example, as noted above, among 18-24 year old men (where ethnic differences are largest), 11.7\% of White claimants were referred for sanction per month compared to $13.8 \%$ of Black, $14.0 \%$ of Mixed, and $12.2 \%$ of Asian claimants. Across almost all ages and genders, claimants of Black and Mixed ethnicity are the most likely to be referred for sanction. The exception to this pattern is 25-49 year old female claimants. Within this group White claimants have the highest referral rates and Asian claimants the lowest. However, the differences between these groups are very small $(5.7 \%$ vs. $5.3 \%$, respectively). Overall, an average of $6.9 \%$ of White claimants were referred for 
sanction per month, compared to $8.0 \%$ of Mixed, $7.3 \%$ of Asian, and $7.2 \%$ of Black claimants.

\section{Do demographic inequalities in referrals persist in rates of actual sanctions?}

Figure 2 gives the rate of final (post-challenge) sanctions by demographic group (underlying figures given in Table A3). These figures show that the demographic inequalities observed at the referral stage persist in the final sanction rate. Younger claimants are more likely to be sanctioned than older claimants; men are more likely to be sanctioned than women; White claimants are (in most age/gender combinations) least likely to be sanctioned, and Black and Mixed claimants are most likely.

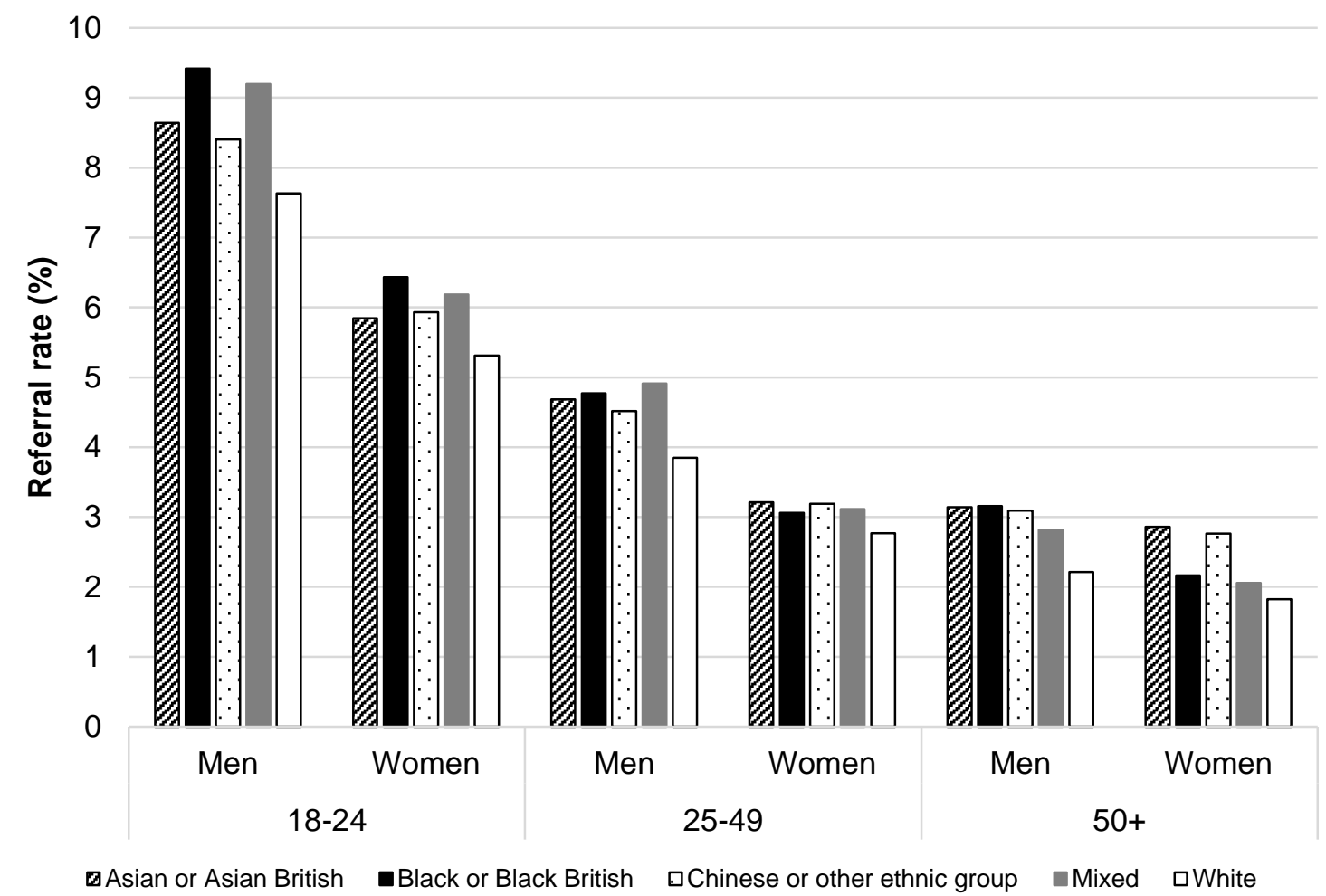

Figure 2. Median percentage of claimants sanctioned per month by age, gender, and ethnicity (Nov 2012-Dec 2016)

Rather than being equalised by the post-referral decision making process, demographic inequalities are in fact amplified. For example:

- White men aged 18-24 are 70\% more likely to be referred for sanction than White men aged 25-49. The relative difference in the rate of actual sanctions is $98 \%$

- Black men aged 18-24 are 36\% more likely to be referred for sanction than Black women in the same age group. The relative difference in the sanction rate is $46 \%$.

- Black men aged 18-24 are 18\% more likely to be referred for sanction than White men in the same age group. The relative difference in the final sanction rate is $23 \%$. 
In some cases, the decision making process also introduces inequalities which were not present at the referral stage. For example, White women aged 25-49 are slightly more likely to be referred for sanction than Asian women of the same age. However, after the decision making process, Asian women in this age group are actually $16 \%$ more likely to be sanctioned than White women.

This amplifying effect of the decision-making process can be seen more clearly in Figure 3 (underlying figures given in Table A4), which shows, for each demographic group, sanctions as a percentage of referrals. Figure 3 shows that, if referred, claimants aged 18-24 are more likely to actually receive a sanction than older age groups. Similarly, within age and ethnic groups, men are more likely to be sanctioned if referred. In terms of ethnicity, in all cases White claimants are the least likely to be sanctioned if referred. Asian claimants and those in the 'Chinese or other' group are, in many cases, the most likely to be sanctioned if referred. This may be due to the fact that members of these groups are less likely to speak English as a native language and may therefore have greater difficulty providing 'good' reasons for breaches when questioned by decision makers, or in mounting a successful challenge to an adverse sanction decision (Reeves \& Loopstra, 2017). This interpretation is supported by the fact that the relative disadvantage of Asian and 'Chinese or other' claimants is largest among the oldest claimants, and among women.

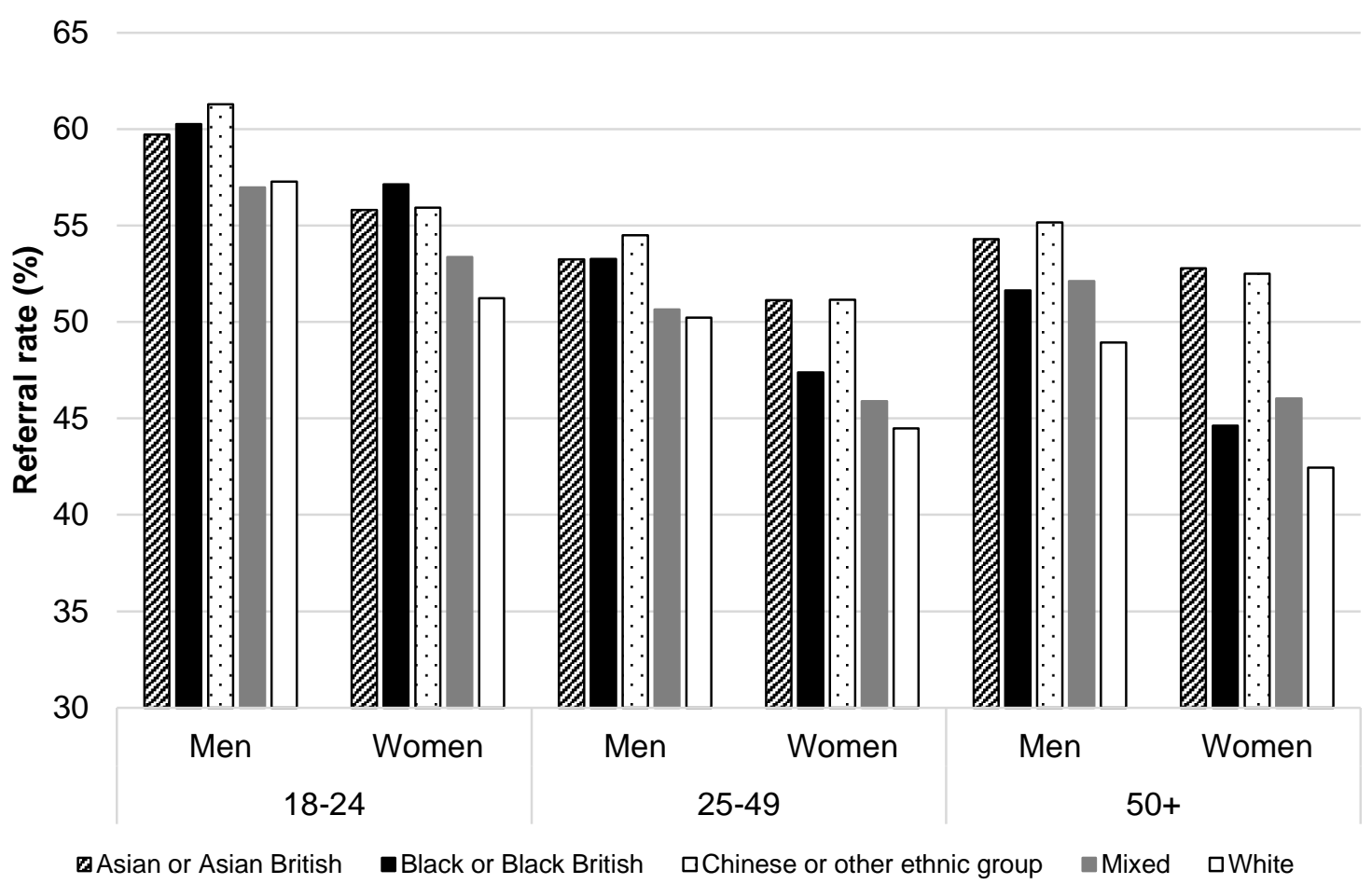

Figure 3. Median number of sanctions as a percentage of referrals by age, gender, and ethnicity (Nov 2012-Dec 2016) 


\section{Are different demographic groups referred for different reasons?}

Figures 4 and 5 gives the proportion of referrals made for each reason for each demographic group (Figure 4 shows results for women and Figure 5 for men; underlying figures are given in Tables A5 and A6). ${ }^{18}$ These figures show that the pattern of referrals is relatively similar across demographic groups. However, there are some notable differences.

First, there are clear age differences in the proportion of referrals made relating to the adviser interview, availability for work, and employment programmes outside the Work Programme. Younger claimants are more likely to be referred for sanction due to failure to attend (which may include being late for) an adviser interview or for failing to comply with a Jobseeker's Direction. Younger claimants are also more likely to be referred for failure to engage with an employment programme. By contrast, claimants aged $50+$ are more likely than those in other age groups to be referred due to problems with being available for work.

There are also some notable differences between ethnic groups. Among both men and women:

- White and 'Chinese or other' claimants are less likely than claimants from other ethnic groups to be referred for reasons relating to the adviser interview

- Asian and 'Chinese or other' claimants are more likely than other claimants to be referred for problems with availability for work

- White claimants are substantially more likely than claimants of other ethnicities to be referred for reasons relating to leaving employment (leaving employment without good reason, or being fired due to misconduct).

Comparing Figures 4 and 5 also shows that male claimants are generally more likely than female claimants to be referred for reasons relating to the adviser interview and for failing to engage with an employment programme. Female claimants are more likely than male claimants to be referred for reasons relating to leaving a job.

\footnotetext{
${ }^{18}$ Some totals sum to more than $100 \%$ because individual claimants may be referred more than once per month. Some totals sum to less than $100 \%$ due to disclosure control: low numbers for some demographic groups within specific referral reasons are suppressed, leading to fewer people being recorded in each reason category than the actual total number of referrals made. For example, there are small numbers of referrals for 'Chinese or other' and Mixed ethnicity claimants in the 50+ age group.
} 


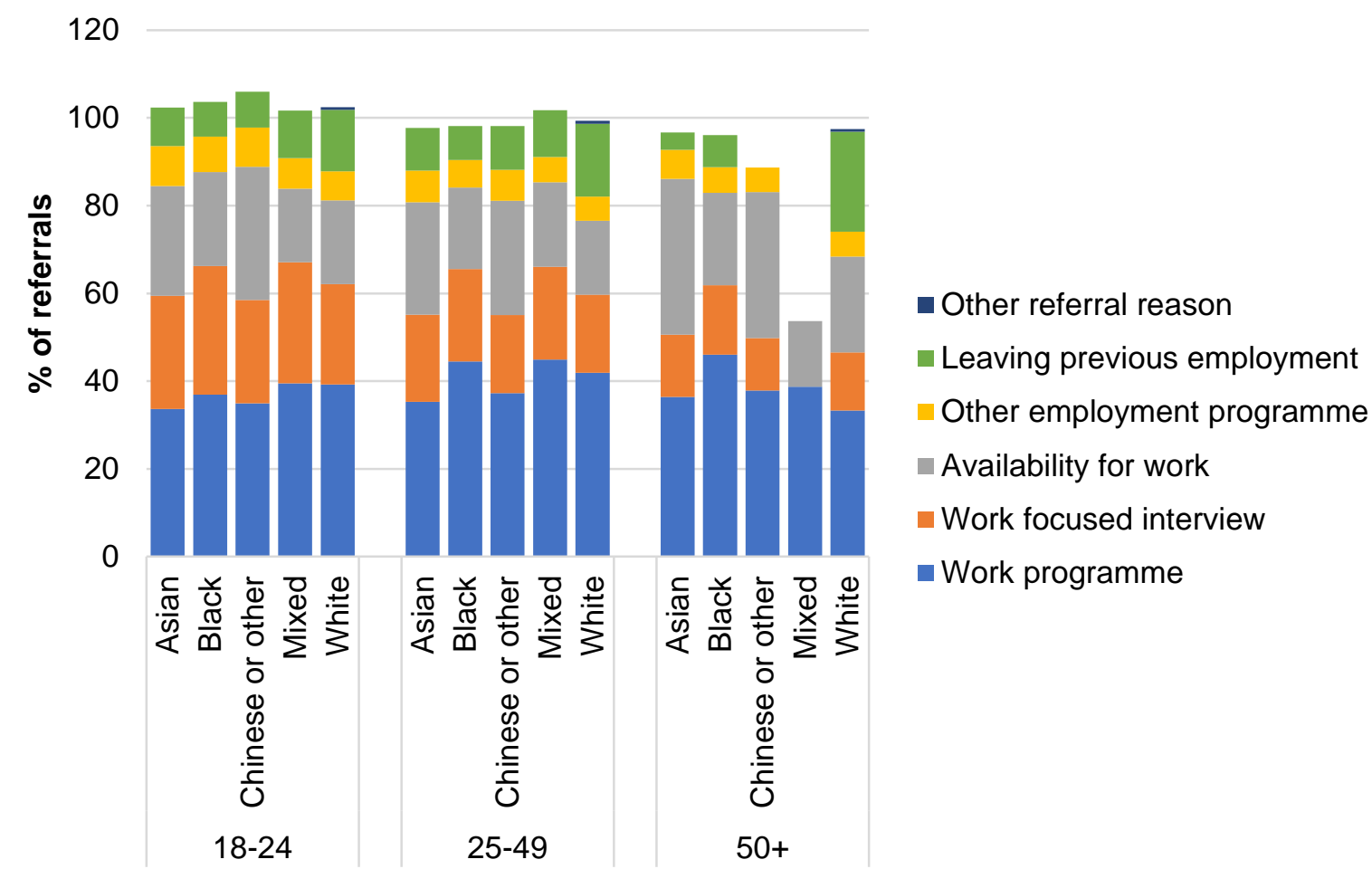

Figure 4. Percentage of referrals made for each referral reason, by age and ethnicity (median month, Nov 2012-Dec 2016) - female claimants

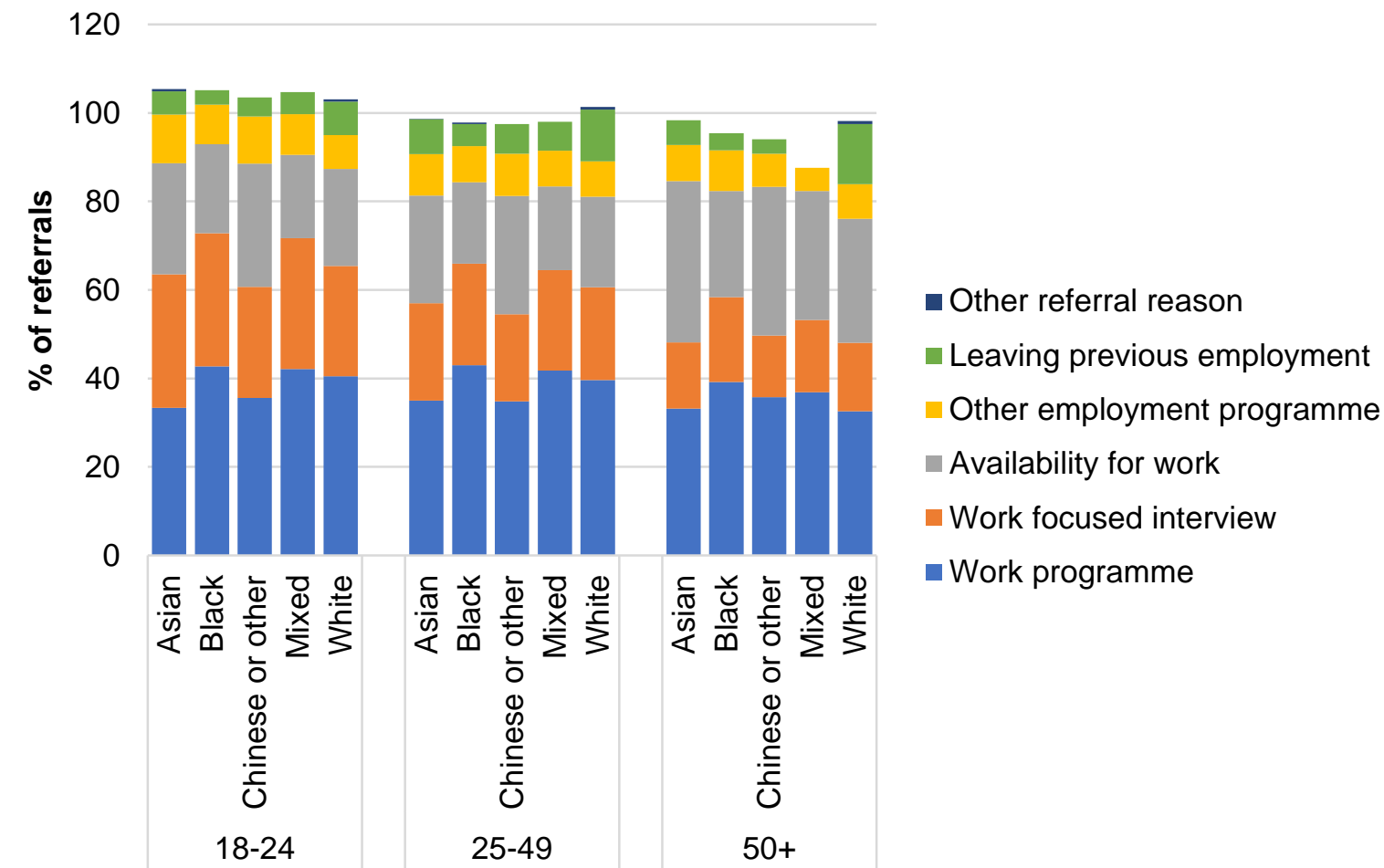

Figure 5. Percentage of referrals made for each referral reason, by age and ethnicity (median month, Nov 2012-Dec 2016) - male claimants 
Have demographic inequalities changed over time?

Figure 6 shows the trend over time in referral rates and sanction rates. Monthly sanction and referral rates peaked in late 2013 , followed by a sharp decline into early 2014. This was followed by a consistent steady decline.

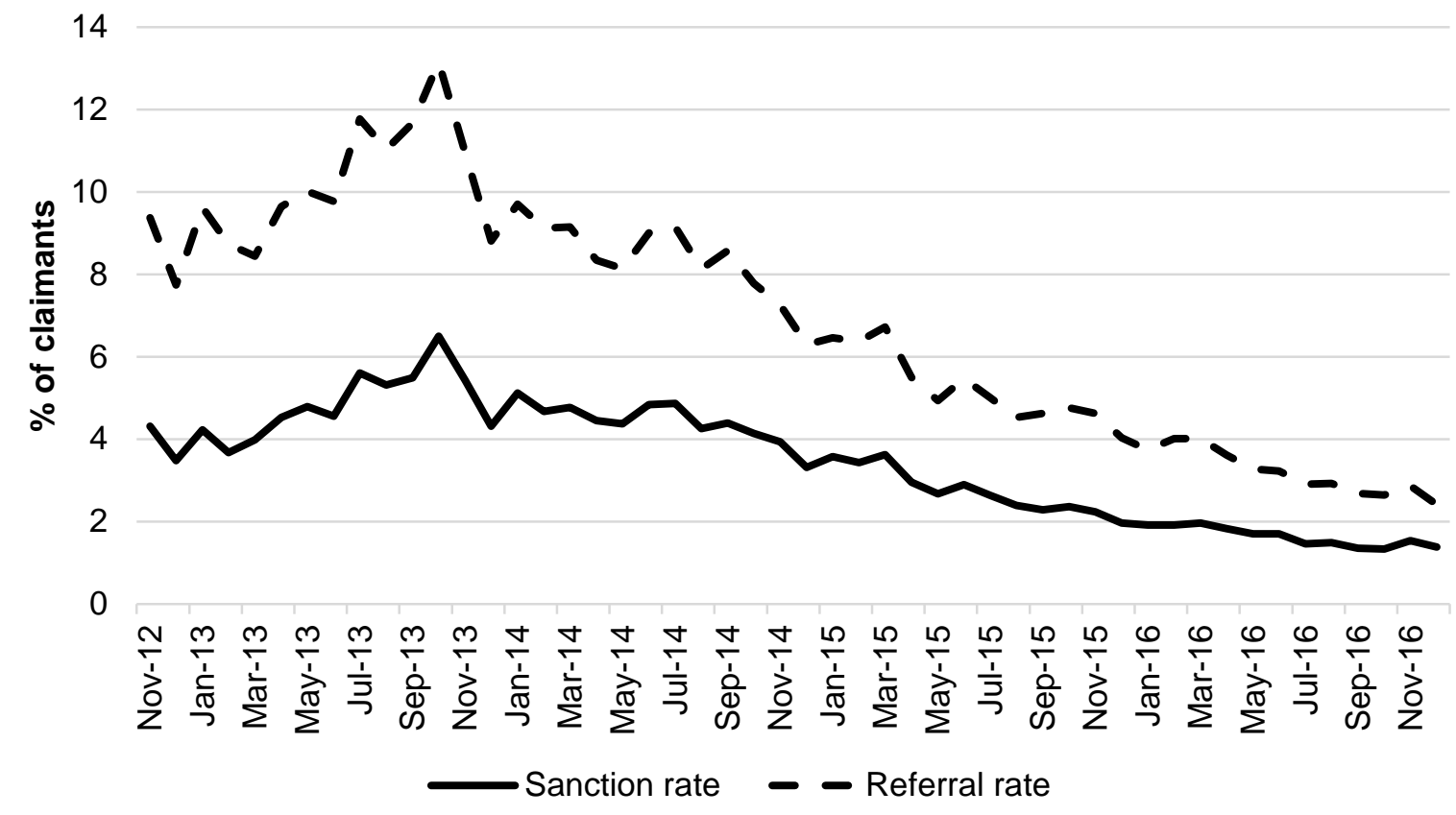

Figure 6. Monthly sanction and referral rate, Nov 2012 - Dec 2016

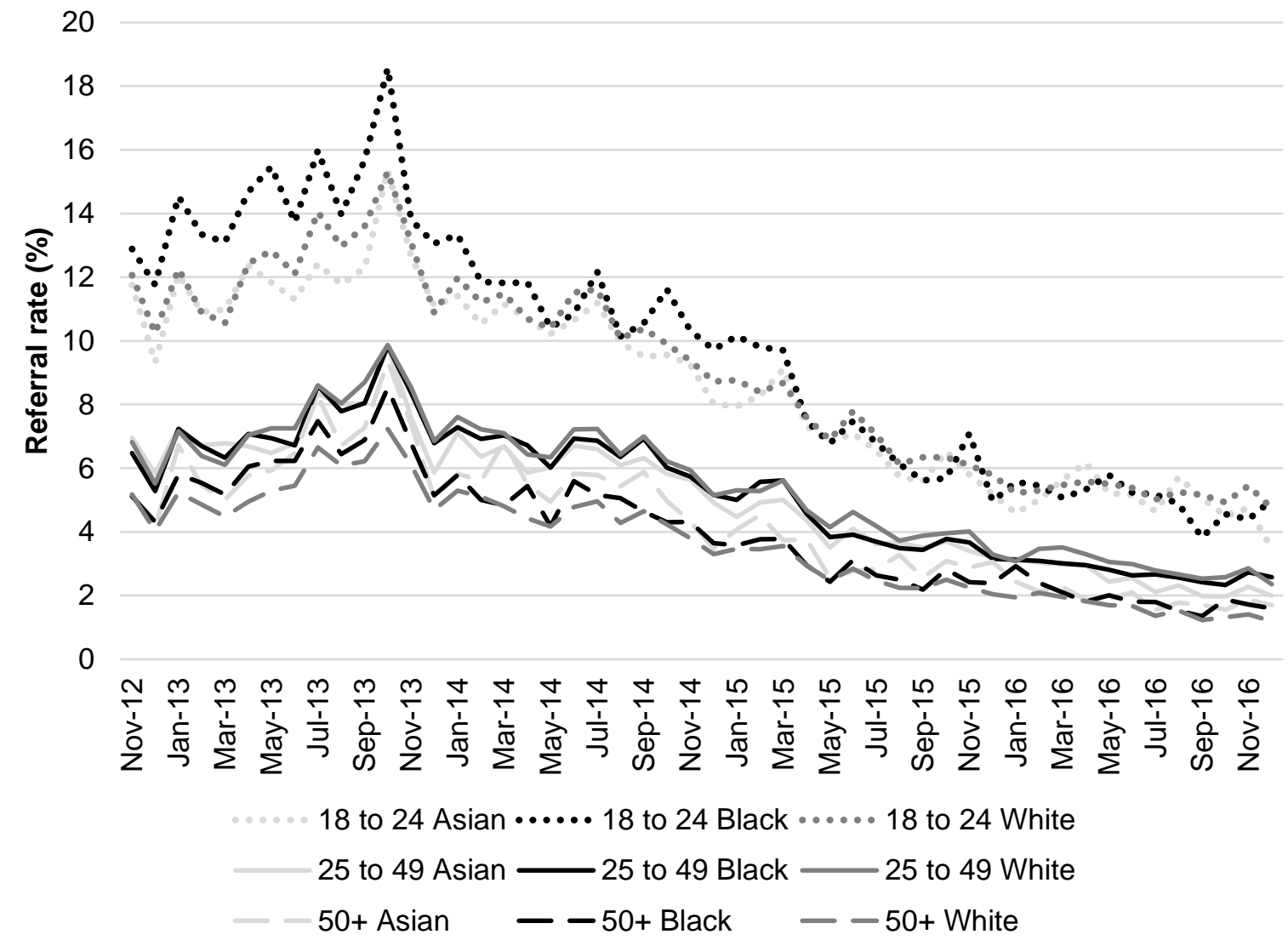

Figure 7. Monthly referral rate by age and ethnicity, Nov 2012 - Dec 2016 (female claimants) 


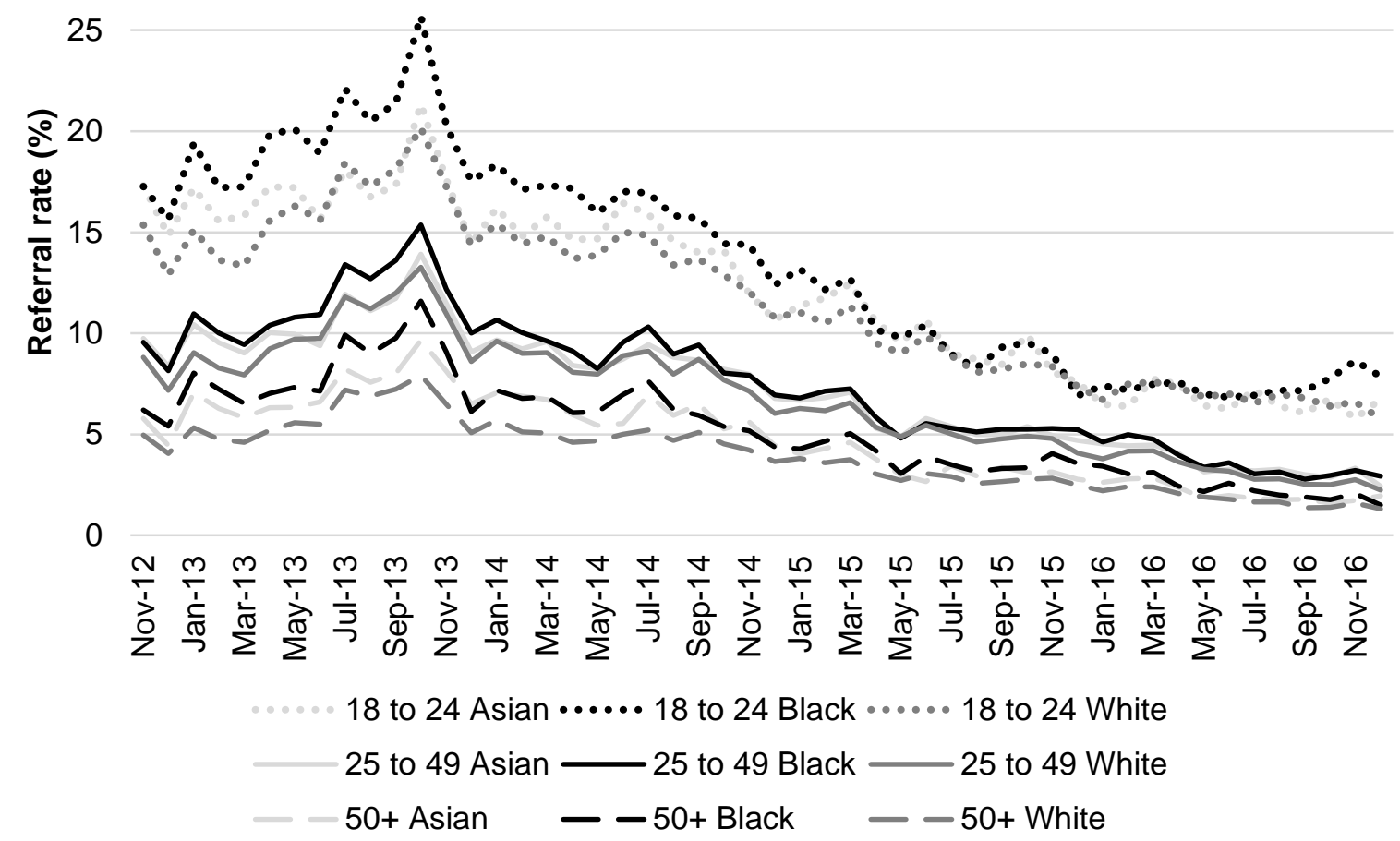

Figure 8. Monthly referral rate by age and ethnicity, Nov 2012 - Dec 2016 (female claimants)

Figures 7 and 8 show trends in referral rates by age and ethnic group for women and men, respectively. For ease of interpretation, only the three largest ethnic groups are plotted. These graphs show that referral rates have followed a generally similar pattern for all demographic groups. However, while age and gender inequalities have remained relatively consistent over the period, differences between ethnic groups have narrowed considerably (though, among men, White claimants remain less likely to be referred for sanction than Black or Asian claimants).

\section{Discussion}

The negative effects of receiving a benefit sanction on mental and physical health have been well documented. The figures given above show that there are substantial demographic inequalities in the risk of receiving a JSA sanction. Some groups of JSA claimants are substantially more likely than others to be referred for a sanction and to have their benefits stopped. The most pronounced differences are those between different age groups. Over the period November 2012 - December 2016, 18-24 year old claimants were substantially more likely to be referred for, and to receive a sanction than were older claimants. For both men and women, and across most ethnic groups, the former were almost twice as likely to be sanctioned as the latter.

The statistics also highlight substantial gender differences. At all ages, and for almost all ethnic groups, men are considerably more likely to be sanctioned than women. 
Ethnic inequalities were generally smaller than those according to age and gender. However, there were consistent patterns. Independent of age and gender, White claimants were less likely to be referred for a sanction, and less likely to ultimately receive a sanction, than were claimants from other ethnic groups. Black claimants and claimants of Mixed ethnicity were generally more likely than claimants from other groups to be referred and sanctioned. These ethnic differences were largest for the group most at risk of sanctions overall: 18-24 year old men. Ethnic differences appear to have narrowed over time, but inequalities persist, particularly among young men.

Why are these groups more likely to be sanctioned than others? Potential explanations fall into two broad camps. The first concerns claimant characteristics and behaviour: claimants in some demographic categories may be genuinely more or less compliant with JSA conditions. This may be due to claimant attitudes towards and engagement with the welfare system. For example, younger claimants may be less reliant on JSA payments (for example, if they receive parental help) and may therefore be less concerned about complying in order to avoid sanctions. Socio-demographic characteristics not captured in the sanctions data, such as English language ability or caring responsibilities, may also make compliance more difficult for some groups, regardless of their motivation to find a job or to avoid sanctions. As Monat (2010) notes in her discussion of the US welfare system, some groups may also suffer discrimination at the hands of employers, which may have knock-on effects on their ability to comply with welfare requirements. For example, experimental research in the UK has shown that employers are often less willing to hire ethnic minority candidates (Wood et al., 2009). Even absent direct discrimination, it is also possible that claimants from certain groups are more likely to live in areas with poorer labour market conditions, which may reduce apparent compliance with the welfare system.

The second category of explanation concerns the treatment of claimants by caseworkers. As noted above, caseworkers enjoy considerable individual discretion (either formal or informal) in the application of sanctions. It is therefore plausible that Jobcentre personal advisers, Work Programme providers, and DWP decision-makers treat members of some demographic groups more harshly than others. For example, older claimants may be treated more leniently due to a perception that they have more difficulty finding work and that they have 'paid more into the system' over the years. Male, and Black and minority ethnic (BME) claimants may also be treated differently due to gender and ethnic stereotypes. An experimental vignette study by Schram et al. (2009) in the US demonstrates how this process might operate. Schram et al. (2009) surveyed around 100 welfare caseworkers with sanctioning authority, using vignettes to present the cases of hypothetical claimants. They found that caseworkers were more likely to sanction a hypothetical Black claimant with a 'discrediting marker' (for example a prior sanction for non-compliance) than an identical White claimant. By contrast, a similar study in Norway found evidence of more lenient treatment of North African as opposed to Norwegian welfare claimants (Terum et al., 2017). As far as we are aware, there have been no studies which have directly examined discrimination 
by welfare caseworkers in the UK (from the perspective of either caseworkers or claimants).

Again, the geographic distribution of claimants from different demographic groups may also play a role, absent direct discrimination. As we have noted, some groups may be more likely to live in areas with poorer labour market prospects. It is possible that caseworkers may treat claimants in these areas more or less leniently in terms of the application of sanctions.

The results presented above cannot distinguish between the potential explanations offered above. However, we intend to expand this working paper to include analyses to address this question. 


\section{Reference list}

Brodkin, E.Z., 1997. Inside the welfare contract: Discretion and accountability in state welfare administration. Social Service Review, 71(1), pp.1-33.

Hagen, J.L. and Owens-Manley, J., 2002. Issues in implementing TANF in New York: The perspective of frontline workers. Social Work, 47(2), pp.171-182.

Longden, J. 2014. Written evidence submitted to the 2014 Work and Pensions Select Committee Inquiry on Benefit sanctions [available at:

http://data.parliament.uk/writtenevidence/committeeevidence.svc/evidencedocument/ work-and-pensions-committee/benefit-sanctions-policy-beyond-the-oakleyreview/written/16165.html]

Loopstra, R., Fledderjohann, J., Reeves, A. and Stuckler, D., 2016. The impact of benefit sanctioning on food insecurity: a dynamic cross-area study of food bank usage in the UK. University of Oxford Sociology Working Papers, 2016-03.

Loopstra, R., Reeves, A., McKee, M. and Stuckler, D., 2015. Do punitive approaches to unemployment benefit recipients increase welfare exit and employment? A crossarea analysis of UK sanctioning reforms. University of Oxford Sociology Working Papers, 2015-01.

Loopstra, R., Reeves, A., Taylor-Robinson, D., Barr, B., McKee, M. and Stuckler, D., 2015a. Austerity, sanctions, and the rise of food banks in the UK. BMJ (Clinical research ed), 350, p.h1775.

Meyers, M.K., Glaser, B. and Donald, K.M., 1998. On the front lines of welfare delivery: Are workers implementing policy reforms?. Journal of policy analysis and management, pp.1-22.

Monnat, S.M., 2010. The color of welfare sanctioning: Exploring the individual and contextual roles of race on TANF case closures and benefit reductions. The Sociological Quarterly, 51(4), pp.678-707.

National Audit Office. 2016. Benefit Sanctions: Report by the Comptroller and Auditor General [available at: https://www.nao.org.uk/wpcontent/uploads/2016/11/Benefit-sanctions.pdf]

New Policy Institute. 2014. Written evidence submitted to the 2014 Work and Pensions Select Committee Inquiry on Benefit sanctions (SAN0156) [available at: http://data.parliament.uk/writtenevidence/committeeevidence.svc/evidencedocument/ work-and-pensions-committee/benefit-sanctions-policy-beyond-the-oakleyreview/written/17368.html]

Pager, D., Bonikowski, B. and Western, B., 2009. Discrimination in a low-wage labor market: A field experiment. American Sociological Review, 74(5), pp.777-799.

Public and Commercial Services Union. 2014. Supplementary written evidence submitted to the 2014 Work and Pensions Select Committee Inquiry on Benefit 
sanctions (SAN0161) [available at:

http://www.parliament.uk/documents/PCS\%20(SAN0161)\%20300115.pdf]

Reeves, A., \& Loopstra, R. (2017). 'Set up to Fail'? How Welfare Conditionality Undermines Citizenship for Vulnerable Groups. Social Policy and Society, 16(2), 327-338.

Schram, S.F., Soss, J., Fording, R.C. and Houser, L., 2009. Deciding to discipline: Race, choice, and punishment at the frontlines of welfare reform. American Sociological Review, 74(3), pp.398-422.

Terum, L.I., Torsvik, G. And Øverbye, E., 2017. Discrimination Against Ethnic Minorities in Activation Programme? Evidence from a Vignette Experiment. Journal of Social Policy, pp.1-18.

Watts, B., Fitzpatrick, S., Bramley, G., and Watkins, D. 2014. Welfare sanctions and conditionality in the UK. Joseph Rowntree Foundation Report [available at:

https://www.jrf.org.uk/file/45777/download?token=8EeV7KdU\&filetype=full-report]

Webster, D. 2016a. Briefing: The DWP's JSA/ESA Sanctions Statistics Release, 17 August 2016 [available at: http://www.cpag.org.uk/sites/default/files/uploads/1608\%20Sanctions\%20Stats\%20Briefing\%20-\%20D\%20Webster.docx]

Webster, D. 2016b. Tackling Britain's misleading benefit sanctions statistics. welfareconditionality.ac.uk [available at:

http://www.welfareconditionality.ac.uk/2016/04/tackling-britains-misleading-benefitsanctions-statistics/]

Wood, M., Hales, J., Purdon, S., Sejersen, T., \& Hayllar, O. 2009. A test for racial discrimination in recruitment in practice in British cities. Department for Work and Pensions Research Report No 607 [available at:

http://www.natcen.ac.uk/media/20541/test-for-racial-discrimination.pdf] 


\section{Appendix}

Table A1. Referral reasons

1. Failure to participate in a scheme for assisting person to obtain employment without good reason - Work Programme

\section{Work focused interviews}

Failure to attend or participate in an adviser interview without good reason

Refusal or failure to comply with a Jobseeker's Direction without good reason

\section{Availability for work}

Not actively seeking employment

Not being available for work

Neglect to avail themselves of a reasonable opportunity of employment without good reason

Refusal or failure to apply for, or accept if offered, a job which an employment officer has informed $\mathrm{him} / \mathrm{her}$ is vacant or about to become vacant without good reason

Jobseeker's Agreement questions

\section{Other employment programmes}

Voluntarily leaves a place on a training scheme or employment programme without good reason

Losing through misconduct a place on a training scheme or employment programme

Refusal of a place on a training scheme or employment programme without good reason

Neglect to avail themselves of a reasonable opportunity of a place on an a training or employment scheme without good reason

Failure to attend a training or employment scheme without good reason

Failure to participate in a scheme for assisting person to obtain employment without good reason -

Skills Conditionality

Failure to participate in a scheme for assisting person to obtain employment without good reason other scheme

Failure to participate in a scheme for assisting person to obtain employment without good reason -

Work Experience

Failure to participate in Mandatory Work Activity without good reason

Failure to participate in supervised job search

\section{Leaving previous employment}

Left employment voluntarily without good reason

Losing employment through misconduct

\section{Other reasons}

Trade disputes

Joint claim exemption

Other referral reason

Table A2. Data for Figure 1

\begin{tabular}{l|cccccc} 
& \multicolumn{2}{|c}{$18-24$} & \multicolumn{2}{c}{$25-49$} & \multicolumn{2}{c}{$50+$} \\
& Men & Women & Men & Women & Men & Women \\
\hline Asian or Asian British & 12.21 & 9.18 & 7.53 & 5.33 & 4.53 & 4.23 \\
Black or Black British & 13.79 & 10.15 & 7.59 & 5.59 & 5.1 & 3.98 \\
Chinese or other & 12.71 & 9.22 & 6.94 & 5.44 & 4.6 & 4.64 \\
ethnic group & 14.03 & 10.39 & 7.75 & 5.52 & 4.74 & 3.91 \\
Mixed & 11.7 & 9.08 & 6.86 & 5.65 & 3.93 & 3.68 \\
White & & & & &
\end{tabular}


Table A3. Data for Figure 2

\begin{tabular}{l|cccccc} 
& \multicolumn{2}{|c}{$18-24$} & \multicolumn{2}{c}{$25-49$} & \multicolumn{2}{c}{$50+$} \\
& Men & Women & Men & Women & Men & Women \\
\hline Asian or Asian British & 8.64 & 5.84 & 4.68 & 3.21 & 3.14 & 2.86 \\
Black or Black British & 9.42 & 6.43 & 4.77 & 3.06 & 3.15 & 2.16 \\
$\begin{array}{l}\text { Chinese or other } \\
\text { ethnic group }\end{array}$ & 8.40 & 5.93 & 4.52 & 3.19 & 3.09 & 2.76 \\
Mixed & & & & & & \\
White & 9.20 & 6.18 & 4.91 & 3.11 & 2.82 & 2.06 \\
& 7.63 & 5.31 & 3.85 & 2.77 & 2.21 & 1.83
\end{tabular}

Table A4. Data for Figure 3

\begin{tabular}{l|cccccc} 
& \multicolumn{2}{|c}{$18-24$} & \multicolumn{2}{c}{$25-49$} & \multicolumn{2}{c}{$50+$} \\
& Men & Women & Men & Women & Men & Women \\
\hline Asian or Asian British & 59.72 & 55.81 & 53.25 & 51.14 & 54.29 & 52.79 \\
Black or Black British & 60.25 & 57.14 & 53.27 & 47.38 & 51.64 & 44.62 \\
$\begin{array}{l}\text { Chinese or other } \\
\text { ethnic group }\end{array}$ & 61.28 & 55.93 & 54.50 & 51.15 & 55.16 & 52.50 \\
Mixed & & & & & & \\
White & 56.97 & 53.37 & 50.64 & 45.90 & 52.12 & 46.03 \\
& 57.28 & 51.24 & 50.22 & 44.49 & 48.94 & 42.45
\end{tabular}

Table A5. Data for Figure 4

\begin{tabular}{|c|c|c|c|c|c|c|c|}
\hline & & $\begin{array}{c}\text { Work } \\
\text { Programme }\end{array}$ & $\begin{array}{l}\text { Work } \\
\text { focused } \\
\text { interview }\end{array}$ & $\begin{array}{l}\text { Availability } \\
\text { for work }\end{array}$ & $\begin{array}{l}\text { Other jobs } \\
\text { programme }\end{array}$ & $\begin{array}{l}\text { Leaving } \\
\text { previous job }\end{array}$ & $\begin{array}{l}\text { Other } \\
\text { referral } \\
\text { reason }\end{array}$ \\
\hline \multirow{5}{*}{$18-24$} & Asian & 33.63 & 25.79 & 25.03 & 9.17 & 8.77 & 0.00 \\
\hline & Black & 36.90 & 29.34 & 21.40 & 8.07 & 7.91 & 0.00 \\
\hline & $\begin{array}{l}\text { Chinese } \\
\text { or other }\end{array}$ & 34.96 & 23.56 & 30.31 & 8.97 & 8.19 & 0.00 \\
\hline & Mixed & 39.50 & 27.57 & 16.77 & 7.02 & 10.82 & 0.00 \\
\hline & White & 39.26 & 22.80 & 19.13 & 6.59 & 14.09 & 0.57 \\
\hline \multirow{5}{*}{$25-49$} & Asian & 35.25 & 19.93 & 25.59 & 7.25 & 9.72 & 0.00 \\
\hline & Black & 44.48 & 21.09 & 18.53 & 6.32 & 7.69 & 0.00 \\
\hline & $\begin{array}{l}\text { Chinese } \\
\text { or other }\end{array}$ & 37.23 & 17.82 & 26.06 & 7.03 & 9.96 & 0.00 \\
\hline & Mixed & 44.95 & 21.08 & 19.28 & 5.79 & 10.67 & 0.00 \\
\hline & White & 41.90 & 17.76 & 16.86 & 5.56 & 16.60 & 0.64 \\
\hline \multirow{5}{*}{$50+$} & Asian & 36.38 & 14.19 & 35.55 & 6.63 & 3.91 & 0.00 \\
\hline & Black & 46.02 & 15.82 & 21.06 & 5.91 & 7.31 & 0.00 \\
\hline & $\begin{array}{l}\text { Chinese } \\
\text { or other }\end{array}$ & 37.87 & 11.93 & 33.33 & 5.56 & 0.00 & 0.00 \\
\hline & Mixed & 38.74 & 0.00 & 14.94 & 0.00 & 0.00 & 0.00 \\
\hline & White & 33.28 & 13.24 & 21.89 & 5.64 & 22.74 & 0.63 \\
\hline
\end{tabular}


Table A6. Data for Figure 5

\begin{tabular}{|c|c|c|c|c|c|c|c|}
\hline & & $\begin{array}{c}\text { Work } \\
\text { Programme }\end{array}$ & $\begin{array}{l}\text { Work } \\
\text { focused } \\
\text { interview }\end{array}$ & $\begin{array}{l}\text { Availability } \\
\text { for work }\end{array}$ & $\begin{array}{l}\text { Other jobs } \\
\text { programme }\end{array}$ & $\begin{array}{c}\text { Leaving } \\
\text { previous } \\
\text { job }\end{array}$ & $\begin{array}{l}\text { Other } \\
\text { referral } \\
\text { reason }\end{array}$ \\
\hline \multirow{5}{*}{$18-24$} & Asian & 33.37 & 30.20 & 25.09 & 11.04 & 5.24 & 0.43 \\
\hline & Black & 42.76 & 30.06 & 20.09 & 8.95 & 3.32 & 0.00 \\
\hline & $\begin{array}{l}\text { Chinese } \\
\text { or other }\end{array}$ & 35.56 & 25.12 & 27.90 & 10.60 & 4.32 & 0.00 \\
\hline & Mixed & 42.09 & 29.61 & 18.87 & 9.17 & 4.99 & 0.00 \\
\hline & White & 40.49 & 24.94 & 21.89 & 7.65 & 7.55 & 0.55 \\
\hline \multirow{5}{*}{$25-49$} & Asian & 34.99 & 22.05 & 24.28 & 9.36 & 7.97 & 0.09 \\
\hline & Black & 42.99 & 22.98 & 18.39 & 8.14 & 4.98 & 0.37 \\
\hline & $\begin{array}{l}\text { Chinese } \\
\text { or other }\end{array}$ & 34.82 & 19.73 & 26.68 & 9.54 & 6.74 & 0.00 \\
\hline & Mixed & 41.81 & 22.66 & 18.94 & 8.04 & 6.58 & 0.00 \\
\hline & White & 39.62 & 20.98 & 20.49 & 7.94 & 11.74 & 0.61 \\
\hline \multirow{5}{*}{$50+$} & Asian & 33.16 & 15.02 & 36.41 & 8.21 & 5.54 & 0.00 \\
\hline & Black & 39.16 & 19.25 & 23.96 & 9.21 & 3.84 & 0.00 \\
\hline & $\begin{array}{l}\text { Chinese } \\
\text { or other }\end{array}$ & 35.73 & 13.97 & 33.61 & 7.51 & 3.24 & 0.00 \\
\hline & Mixed & 36.87 & 16.38 & 29.12 & 5.27 & 0.00 & 0.00 \\
\hline & White & 32.61 & 15.48 & 28.03 & 7.82 & 13.59 & 0.63 \\
\hline
\end{tabular}

